(c) 2017, THE AUTHORS. Published by FASS and Elsevier Inc. on behalf of the American Dairy Science Association ${ }^{\circledR}$.

This is an open access article under the CC BY-NC-ND license (http://creativecommons.org/licenses/by-nc-nd/3.0/).

\title{
Evaluation of a gas in vitro system for predicting methane production in vivo
}

\author{
Rebecca Danielsson, ${ }^{* 1}$ Mohammad Ramin, $\dagger^{1}$ Jan Bertilsson, ${ }^{*}$ Peter Lund, $\ddagger$ and Pekka Huhtanen $†$ \\ *Department of Animal Nutrition and Management, Swedish University of Agricultural Sciences, SE-75323, Uppsala, Sweden \\ †Department of Agricultural Research for Northern Sweden, Swedish University of Agricultural Sciences, SE-901 83, Umeå, Sweden \\ †Department of Animal Science, Aarhus University, AU Foulum, PO Box 50, DK 8830 Tjele, Denmark
}

\section{ABSTRACT}

Methane production from ruminant livestock varies with the diet as a result of factors such as dry matter intake, diet composition, and digestibility. To estimate the effect of dietary composition and feed additives, $\mathrm{CH}_{4}$ production can be measured in vitro as a first step because large numbers of samples can be incubated and analyzed at the same time. This study evaluated a recently developed in vitro method for prediction of in vivo $\mathrm{CH}_{4}$ production by examining the relationship between predicted and observed $\mathrm{CH}_{4}$ production values. A total of 49 different diets (observations), used in previous 13 in vivo studies, were selected to include diets varying in nutrient composition. Methane production was measured in all in vivo studies by respiration chambers or the GreenFeed system (C-Lock Inc., Rapid City, SD). Overall, the in vitro system predicted $\mathrm{CH}_{4}$ production well $\left(\mathrm{R}^{2}=0.96\right)$, but the values obtained were slightly underestimated compared with observed in vivo values (mean $399 \mathrm{~L} / \mathrm{d}$ compared with $418 \mathrm{~L} / \mathrm{d}$ : root mean square prediction error $=51.6 \mathrm{~L} / \mathrm{d}$ or $12.3 \%$ of observed mean). Further analysis of the effect on residuals showed no significant relationship between $\mathrm{CH}_{4}$ production and most factors known to affect $\mathrm{CH}_{4}$ production such as dry matter intake, digestibility, and dietary concentrations of fat and starch. However, some factors included in the model were not well predicted by the system, with residuals negatively related to neutral detergent fiber concentration and positively related to concentrate proportion. The in vitro system can thus be useful for screening diets and evaluation of feed additives as a first step that can be best interpreted when feeding cows at maintenance level.

Key words: in vitro, in vivo, predicting methane production

Received February 1, 2017.

Accepted July 14, 2017.

${ }^{1}$ Corresponding authors: rebecca.danielsson@slu.se and mohammad. ramin@slu.se

\section{INTRODUCTION}

Methane is one of the major greenhouse gases. Dairy cows contribute $\mathrm{CH}_{4}$ to the atmosphere due to microbial fermentation of feed in the rumen and hindgut. The production of $\mathrm{CH}_{4}$ by ruminants also causes energy losses for the animal, corresponding to 2 to $12 \%$ of gross energy (GE) intake (Johnson and Johnson, 1995). The total amount of $\mathrm{CH}_{4}$ released is dependent on several factors, such as DMI, type of feed, feed quality, and OM digestibility (Johnson and Johnson, 1995; Ramin and Huhtanen, 2013). Different strategies have been evaluated with the aim of reducing enteric $\mathrm{CH}_{4}$ production and interesting possibilities are offered by feed supplements [e.g., dietary fat, ionophores, plant compounds, and enzymes (Beauchemin et al., 2009; Hook et al., 2010; Knapp et al., 2014)]. To evaluate the effect of dietary composition and feed additives, reliable measurement of $\mathrm{CH}_{4}$ production is essential. Some common in vivo measurement techniques are available, all of which have advantages and disadvantages in terms of, for example, accuracy and cost. The most consistent is the respiration chamber technique, where the concentrations of $\mathrm{CH}_{4}$ and $\mathrm{CO}_{2}$ in air flux (L/min) are measured (Johnson and Johnson, 1995; Yan et al., 2010), but this technique is very costly and is not suitable for measurements on many animals at the same time. Another technique that can be used for on-farm measurements is the sulfur hexafluoride $\left(\mathrm{SF}_{6}\right)$ tracer technique (Johnson et al., 1994), which is based on the ratio of $\mathrm{SF}_{6}$ to $\mathrm{CH}_{4}$. Results obtained using this technique show higher variation than chamber values (Hammond et al., 2009). Yet another technique that can be used to estimate total daily $\mathrm{CH}_{4}$ emissions of individuals is based on spot sampling over several days of breath in feed troughs in automatic milking systems or in concentrate feeders, such as the GreenFeed system (C-Lock Inc., Rapid City, SD) and the spot sampling method used by Madsen et al. (2010). These techniques may give higher variation than chamber techniques, but this can be compensated for by a large number of animals for measurements. 
However, in vivo studies are expensive and to reduce costs and effects on animals, various in vitro systems have been developed. Continuous culture experiments as described by Czerkawski and Breckenridge (1977) and batch culture experiments as reported by van Nevel and Demeyer (1981) are commonly used for evaluating the effects of diets and additives on enteric $\mathrm{CH}_{4}$ production. Recently, Ramin and Huhtanen (2012) developed an in vitro method for prediction of $\mathrm{CH}_{4}$ production in the rumen of cows using the kinetic parameters from an automated in vitro gas production (GP) system in a 2-compartment rumen model. This approach takes rumen dynamics (digestion kinetics) into account and may have advantages compared with single time point batch culture systems. However, in vitro techniques are applied to predict treatment effects in vivo, and it is therefore important that these techniques are reliable and well validated. In the review of Yáñez-Ruiz et al. (2016) where the designs, implementation, and interpretation of in vitro batch systems were reviewed, it was proposed that studies with direct comparisons between in vitro and in vivo systems would allow better interpretation of data and treatments suitable for evaluating the in vitro GP system. The aim of this study was to investigate the potential of the in vitro GP system for ranking different type of diets according to predicted $\mathrm{CH}_{4}$ production, compared with in vivo $\mathrm{CH}_{4}$ production values.

\section{MATERIALS AND METHODS}

\section{Studies and Treatments}

The diets for which in vitro $\mathrm{GP}$ and $\mathrm{CH}_{4}$ production were predicted were selected from 13 different in vivo studies and consisted of 49 diets in total (Ap- pendix). The majority of these diets were formulated based on a larger data set previously used to develop prediction equations for methane production (Ramin and Huhtanen, 2013). They were selected to include different dietary composition: feeding levels, proportion of concentrate, carbohydrate composition of concentrates, protein and fat supplementation, forage type, and maturity of forage (Table 1). Measurement of $\mathrm{CH}_{4}$ production in the original in vivo studies was mainly performed in respiration chambers, with the exception of the study by Gidlund et al. (2015) where the GreenFeed system was used (C-Lock Inc.). In 4 cases, the original ingredients used in the in vivo studies (21 diets) were also used for the in vitro system. The in vitro diets for the remaining 9 of the 13 in vivo studies (28 diets) were formulated to be as similar as possible to the original feeds used in vivo in terms of ingredient composition and concentrations of $\mathrm{ME}, \mathrm{CP}$, and NDF. Digestibility of silage samples was determined either in vivo in sheep or in vitro. Ingredients for those 9 studies were provided by the Swedish University of Agricultural Sciences Research Centers in Umeå and Uppsala (Sweden), LUKE National Resources Institute (Finland), and the feed companies Raisio Ltd. (Raisio, Finland) and Teknosan (Vänersborg, Sweden).

\section{Animals, Experimental Design, and Laboratory Procedures}

The study was performed at the Swedish University of Agricultural Sciences in Umeå, Sweden. All handling of animals was approved by the Umeå Ethics Committee for Animal Research, Sweden. Three dairy cows of the Swedish Red breed in late lactation, fed a TMR (grass silage/concentrate ratio 600/400 g/ $/ \mathrm{kg}$ on a DM basis) ad libitum, were used as donors of ru-

Table 1. Description of diets and type of animal used in in vivo studies for which original ${ }^{1}$ or constructed diets were analyzed in vitro

\begin{tabular}{|c|c|c|c|}
\hline Diet & Reference & Forage & $\begin{array}{c}\text { Animal } \\
\text { type }^{2}\end{array}$ \\
\hline $1-4$ & Ferris et al., 1999 & Grass silage and different proportions of concentrate & 1 \\
\hline $5-7$ & Keady and Mayne, 1998 & Grass silage and different energy sources for concentrate & 1 \\
\hline $8-11$ & Beever et al., 1988 & Grass silage cut at different date and barley substitution & 3 \\
\hline $12-15$ & Kirkpatrick et al., 1997 & Different types of grass silage and different levels of concentrate & 2 \\
\hline $16-17$ & Gordon et al., 1995 & Grass silage and different types of concentrate & 1 \\
\hline $18-20$ & Jentsch et al., 1972 & Hay, different levels of added canola oil & 1 \\
\hline $21-23$ & Moss et al., 1995 & Grass silage and different levels of barley & 4 \\
\hline $24-26$ & Moss and Givens, 2002 & Grass silage and supplementation with soybean meal & 4 \\
\hline $27-28$ & Tyrrell et al., 1992 & Direct-cut alfalfa or orchard grass ensiled & 3 \\
\hline $29-32$ & Brask et al., 2013a & Corn and grass silage and different physical forms of canola & 1 \\
\hline $33-38$ & Brask et al., 2013b & Early/late grass silage or corn silage, with/without canola oil supplement & 1 \\
\hline $39-45$ & Gidlund et al., 2015 & Grass silage and soybean meal or canola meal & 1 \\
\hline $46-49$ & Hellwing et al., 2013 & Grass silage and different types of treated wheat & 1 \\
\hline
\end{tabular}

\footnotetext{
${ }^{1}$ Original diets were also used in vitro for diets 29 to 49.

${ }^{2} 1=$ dairy cows; 2 = beef cattle; $3=$ growing cattle; $4=$ sheep.
} 
Table 2. Nutritional content of replacement diets for constructed diets 1 to 28 ( $\mathrm{g} / \mathrm{kg}$ of DM unless otherwise stated)

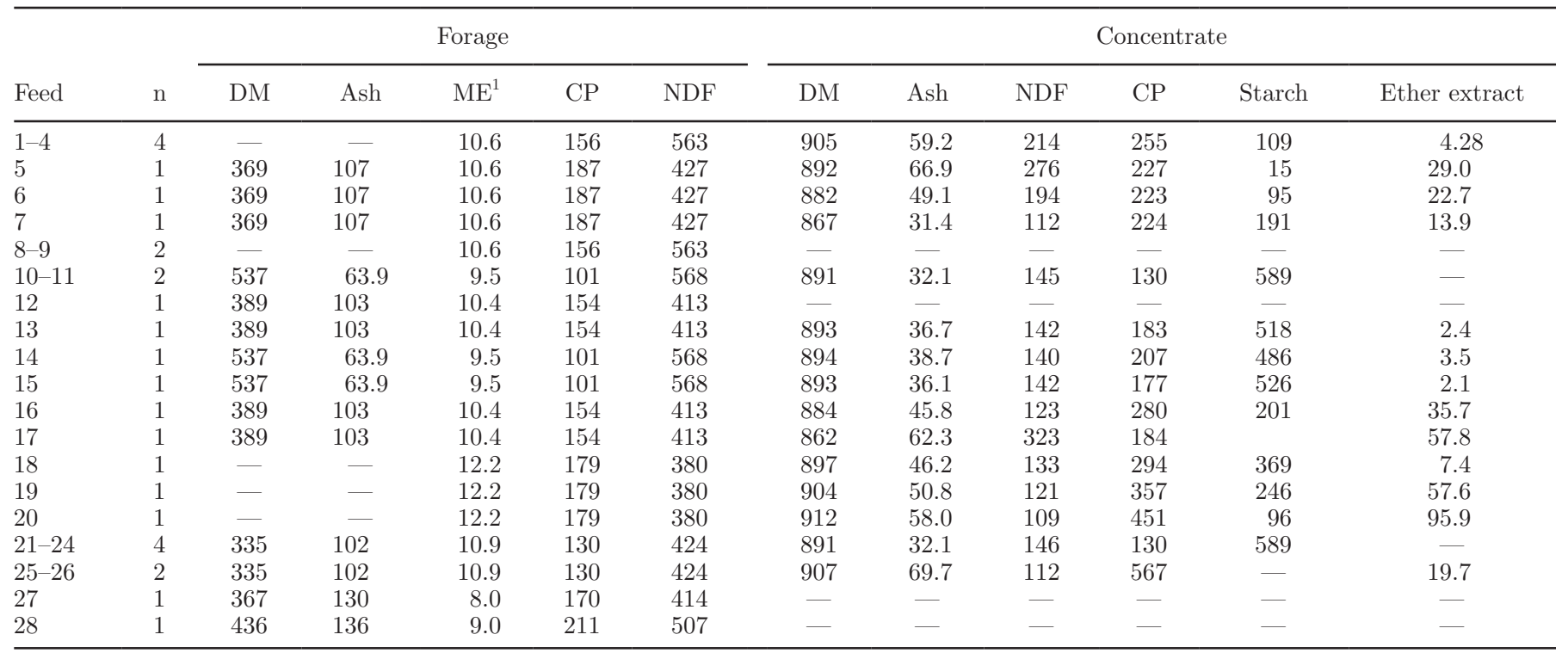

${ }^{1} \mathrm{MJ} / \mathrm{kg}$ of DM.

men inoculum. Rumen fluid was collected $2 \mathrm{~h}$ after the morning feeding. The rumen fluid from these cows was strained separately through a double layer of cheesecloth into pre-warmed thermos flasks that had been flushed with $\mathrm{CO}_{2}$, transported to the laboratory within 10 min after collection, and pooled on an equal volume basis. The pooled rumen fluid was strained through 4 layers of cheesecloth and mixed (20:80 vol/vol) with buffered mineral solution (Menke and Steingass, 1988) supplemented with peptone (pancreatic digested casein, Merck, Darmstadt, Germany) at $39^{\circ} \mathrm{C}$ under constant stirring and continuous flushing with $\mathrm{CO}_{2}$.

Samples of silage and concentrate were dried at $60^{\circ} \mathrm{C}$ in a forced air oven for $48 \mathrm{~h}$ and milled through a 1-mm screen using a Retsch mill (Retsch, SM 2000, Rheinische, Haan, Germany). The samples were then stored in sealed glass jars at room temperature and used for chemical analysis. Conventional chemical analyses for DM, NDF assayed with heat-stable amylase and expressed exclusive of residual ash [amylase-treated neutral detergent fiber organic matter (aNDFom)], $\mathrm{CP}$, starch (for concentrate), ash, and calculated ME were performed using standard methods as described by Bertilsson and Murphy (2003). Nutritional content for each replacement feed is presented in Table 2, and average nutrient composition for all replacement feeds used to reconstitute diets in Table 3.

Prior to in vitro incubation, 1,000-mg portions of substrate in accordance with the reference diet composition were weighed into serum bottles $(250 \mathrm{~mL}$, Schott, Mainz, Germany). All bottles were filled with $60 \mathrm{~mL}$ of buffered rumen fluid and placed in a water bath at $39^{\circ} \mathrm{C}$ for $48 \mathrm{~h}$ under continuous agitation. Each diet was randomly distributed in 3 runs out of a total of 5 runs. Two bottles with no substrate added were included as blanks in each run.

Total GP in the in vitro system was recorded with an automated system (Cone et al., 1996) with readings ev-

Table 3. Average nutrient content in replacement diets ( $\mathrm{g} / \mathrm{kg}$ of $\mathrm{DM}$ unless otherwise stated), $\mathrm{n}=28$

\begin{tabular}{|c|c|c|c|c|c|c|c|c|}
\hline Item & \multicolumn{4}{|c|}{ Silage } & \multicolumn{4}{|c|}{ Concentrate } \\
\hline$\overline{\mathrm{DM}}$ & 401 & 76.8 & 335 & 537 & 893 & 12.5 & 862 & 912 \\
\hline $\mathrm{ME}$ & 10.4 & 0.86 & 8.0 & 12.2 & - & - & - & - \\
\hline $\mathrm{CP}$ & 150 & 29.2 & 101 & 211 & 165 & 56.4 & 109 & 323 \\
\hline NDF & 474 & 73.8 & 380 & 560 & 248 & 130.6 & 130 & 567 \\
\hline
\end{tabular}


ery $12 \mathrm{~min}$, and corrected to normal air pressure (101.3 $\mathrm{kPa}$ ). Mean blank GP within each run was subtracted from the sample GP. To analyze $\mathrm{CH}_{4}$ production, gas samples were collected using a gas-tight syringe $(1 \mathrm{~mL}$, Hamilton, Bonaduz, Switzerland) from the headspace (HS) of each bottle after 2, 4, 8, 24, 32, and $48 \mathrm{~h}$ of incubation. Methane concentration was measured for each bottle by injecting $0.2 \mathrm{~mL}$ of $\mathrm{HS}$ gas into a gas chromatograph (Varian Chromatography, Palo Alto, $\mathrm{CA}$ ). The gas chromatograph (Varian Chromatography) was equipped with a thermal conductivity detector. Separation was achieved using a 1-m-long stainless steel column packed with Haysept T (80 to 100 mesh), argon as the carrier gas with a flow rate of $32 \mathrm{~mL} /$ min, and an isothermal oven temperature of $32^{\circ} \mathrm{C}$. The injector and detector temperature were set to 110 and $135^{\circ} \mathrm{C}$, respectively. Calibration gas was completed using a standard mixture of $\mathrm{CO}_{2}$ and methane (100 $\mathrm{mmol} / \mathrm{mol}$ ) prepared by AGA Gas (AGA Gas AB, Sundbyberg, Sweden). Peaks were identified by comparison with the standard gas. Methane production in vivo was predicted using a modeling approach described by Ramin and Huhtanen (2012). In brief, based on the kinetic data on $\mathrm{CH}_{4}$ production obtained from in vitro GP, the cumulative $\mathrm{CH}_{4}$ production $(\mathrm{mL})$ at each time point $(0.2 \mathrm{~h})$ was calculated as

$$
\begin{aligned}
& \text { total } \mathrm{CH}_{4} \text { production }(\mathrm{mL})=\mathrm{HS} \text { volume }(\mathrm{mL}) \\
& \times \mathrm{HS} \mathrm{CH}_{4} \text { concentration }(\mathrm{mL} / \mathrm{mL})+\text { total } \mathrm{GP}(\mathrm{mL}) \\
& \times \mathrm{A} \times \mathrm{HS} \mathrm{CH}_{4} \text { concentration }(\mathrm{mL} / \mathrm{mL}),
\end{aligned}
$$

where the total HS volume per bottle and connected pressure tubes was $265 \mathrm{~mL}$, and $\mathrm{A}$ is the ratio of $\mathrm{CH}_{4}$ concentration in outflow gas (= measured GP) to $\mathrm{CH}_{4}$ concentration in HS gas. Because the outflow gas could not be collected in the system, A was predicted using a mechanistic model, as described by Ramin and Huhtanen (2012), using stoichiometric principles and assuming that $1 \mathrm{~mol}$ of VFA released $1 \mathrm{~mol}$ of $\mathrm{CO}_{2}$. Methane concentration at time intervals of $0.2 \mathrm{~h}$ was estimated by a logarithmic model of time versus $\mathrm{CH}_{4}$ concentration. Kinetic parameters such as volume (V, $\mathrm{mL} / \mathrm{g}$ of $\mathrm{DM})$, lag $(\mathrm{l}, \mathrm{h})$, and rate $(\mathrm{k}, / \mathrm{h})$ for rapid and slow were estimated by fitting the 2-pool Gompertz function model to the $\mathrm{CH}_{4}$ data (Schofield et al., 1994), using the NLIN procedure in the SAS program (version 9.3, SAS Inst. Inc., Cary, NC). The parameters were then subjected to a dynamic, mechanistic 2-compartment rumen model described by Huhtanen et al. (2008), which estimated the proportion of asymptotic $\mathrm{CH}_{4}$ production at infinite time $\left(\mathrm{V}_{1}+\mathrm{V}_{2}\right)$ produced during the residence of feed in the rumen for a given time $\left(\mathrm{CH}_{4}\right.$-prop). Methane production $(\mathrm{mL} / \mathrm{g}$ of $\mathrm{DM})$ was calculated as $\mathrm{CH}_{4}$-prop $\times$ asymptotic $\mathrm{CH}_{4}$ production $(\mathrm{mL} / \mathrm{g}$ of $\mathrm{DM})$. The effective first-order $\mathrm{CH}_{4}$ production rate was estimated by solving the 2-compartment equation described by Allen and Mertens (1988) for kd when digestibility (here proportion) and passage kinetic parameters are known. Passage rate $\left(k_{p}\right)$ for each diet was calculated from NDF intake per kilogram of BW based on the empirical relationship between NDF intake as a proportion of $\mathrm{BW}$ and NDF passage rate derived from rumen evacuation data (Krizsan et al., 2010):

$$
\begin{aligned}
k_{p}(1 / \mathrm{h})=0.0177 & +\mathrm{NDF} \text { intake }(\mathrm{g} / \mathrm{kg} \text { of } \mathrm{BW}) \\
& \times 0.00076 .
\end{aligned}
$$

According to Cannas et al. (2003), the passage rate of concentrate particles is 1.6 times faster than the passage rate of forage particles. The passage rate for forage and concentrate can then be calculated from the passage rate of the whole diet and known proportions of forage (F-) and concentrate (C-) NDF in dietary NDF:

$$
\begin{gathered}
\text { forage } k_{p}(1 / \mathrm{h})=k_{p} \times(\mathrm{C}-\mathrm{NDF}+1.6 \times \mathrm{F}-\mathrm{NDF}) / \\
{[1.6 \times(\mathrm{C}-\mathrm{NDF}+\mathrm{F}-\mathrm{NDF})]} \\
\text { concentrate } k_{p}(1 / \mathrm{h})=1.6 \times \text { forage } k_{p}(1 / \mathrm{h})
\end{gathered}
$$

Total retention time $\left(\mathbf{R T} ; 1 / k_{p}\right)$ was divided between a nonescapable (large particles) and escapable pool (small particles) in the ratio of 20:80 for concentrates and 30:70 for forage (Danfær et al., 2006). Passage kinetic parameters for concentrates were used for the fast pool $\left(V_{1}\right)$ and those for forage for the slow pool $\left(V_{2}\right)$. Predicted mean RT for total diets in this study varied from 34.2 to $51.1 \mathrm{~h}$. The model is programmed in Excel (Microsoft Corp., Redmond, WA): the simulations were run for $120 \mathrm{~h}$ with a 0.05 -h integration step and using the model described by Huhtanen et al. (2008).

\section{Statistical Analysis}

Before analyzing the relationship between observed and predicted values, outliers were identified by PROC MIXED in SAS (version 9.3, SAS Institute Inc.) by comparing predicted values with values produced by the statistical model, taking into account feed effects and random run effects. Observations with residuals smaller or greater than 2 standard deviation units of the mean were removed from the data set. Least 
squares means for each diet were estimated in PROC MIXED by the model:

$$
\text { predicted } \mathrm{CH}_{4}=\operatorname{run}_{i}+\operatorname{diet}_{j}+e_{i j k} \text {, }
$$

where $i=3$ for run, $j=49$ for diet, and $e_{i j k}$ is a random error term. The relationship between predicted and observed $\mathrm{CH}_{4}$ emissions was assessed using the linear regression technique (FIXED model). The relationship between predicted and observed values was also evaluated for a subset of data where original feeds from in vivo experiments were used in vitro $(j=21)$. The performance of the in vitro technique in predicting in vivo $\mathrm{CH}_{4}$ emissions was further evaluated using the MIXED regression model procedure of SAS (Littell et al., 1996) with random study effect. The relationship between independent and dependent variables was estimated using the following model:

$$
Y_{i j k}=B_{0}+B_{1} X_{1 i j}+b_{0}+b_{1} X_{1 i j}+e_{i j k},
$$

where $B_{0}$ and $B_{1} X_{1 i j}$ are fixed effects (intercept and effects of independent variables) and $b_{0}$ (intercept), $b_{1}$ (slope), and $e_{i j}$ are random experiment effects $(i=1$, $\ldots, 13$ studies and $j=1, \ldots, n_{i}$ values). Root mean square prediction error (RMSPE) was calculated as

$$
\text { RMSPE }=\sqrt{ }\left[\Sigma(\text { observed }- \text { predicted })^{2} / n\right] .
$$

The error was also expressed as a proportion of the observed mean to give an estimate of the overall prediction error. To center the predicted values, the overall predicted mean value was subtracted from each predicted value. This made the slope and intercept estimates orthogonal, and thereby independently assessable. Residual analysis was conducted as described by St-Pierre (2003) for $\mathrm{CH}_{4}$ emissions, by regressing the centered predicted values against the residuals (observed-predicted $\mathrm{CH}_{4}$ emissions). To estimate sources of bias, a regression analysis was conducted between the residuals of $\mathrm{CH}_{4}$ emissions and variables identified as affecting $\mathrm{CH}_{4}$ emissions, such as total DMI, OM digestibility, and dietary concentrations of NDF, starch, CP, and ether extract.

\section{RESULTS}

\section{Diets}

All diets tested in the study were assumed to cover differing dietary compositions, see Table 1 . The mean DMI was $13.4 \mathrm{~kg}$ of $\mathrm{DM} / \mathrm{d}$ and the concentration of $\mathrm{NDF}$ and CP was 396 and $182 \mathrm{~g} / \mathrm{kg}$ of DM, respectively.

\section{Prediction of $\mathrm{CH}_{4}$ Emissions from the In Vitro System}

All diets were run in 3 or 4 replicate incubations, resulting in a total of 167 observations for the 49 diets. Six of the observations were identified as outliers and removed from the data set, 4 values were single observations in a diet and 2 values were from the same diet.

The in vitro system slightly underestimated $\mathrm{CH}_{4}$ production compared with observed in vivo values (399 $\mathrm{L} / \mathrm{d}$ compared with $418 \mathrm{~L} / \mathrm{d}$; Table 4 ). The relationship between predicted and observed $\mathrm{CH}_{4}$ emissions is shown in Figure 1. The following linear relationships were developed with the fixed regression model:

$$
\begin{aligned}
& \text { observed } \mathrm{CH}_{4}(\mathrm{~L} / \mathrm{d})=0.92( \pm 0.034) \\
& \times \text { predicted } \mathrm{CH}_{4}(\mathrm{~L} / \mathrm{d})+49( \pm 15.6)
\end{aligned}
$$

with $\mathrm{R}^{2}=0.94$ and RMSPE $=51.6 \mathrm{~L} / \mathrm{d}(12.3 \%$ of observed mean). When using the mixed regression model, the linear relationship was as follows:

$$
\begin{aligned}
& \text { observed } \mathrm{CH}_{4}(\mathrm{~L} / \mathrm{d})=0.88( \pm 0.050) \\
& \times \text { predicted } \mathrm{CH}_{4}(\mathrm{~L} / \mathrm{d})+63( \pm 21.3)
\end{aligned}
$$

with $\mathrm{R}^{2}=0.96$ and RMSPE $=40.1 \mathrm{~L} / \mathrm{d}(9.5 \%$ of observed mean). When predicted values were centered, the intercept was significant $(P \leq 0.01)$ with the fixed model, but not $(P=0.19)$ with the mixed model. Slope bias was significant with both the fixed and mixed model ( $P=0.03$ and $P \leq 0.01$, respectively). When only the original feeds used in vivo were incubated in vitro and were evaluated separately by fixed regression model (Figure 2), the linear relationship was as follows:

$$
\begin{gathered}
\text { observed } \mathrm{CH}_{4}(\mathrm{~L} / \mathrm{d})=0.81( \pm 0.172) \\
\times \text { predicted } \mathrm{CH}_{4}+127( \pm 94.7)
\end{gathered}
$$

with $\mathrm{R}^{2}=0.54$ and RMSPE $=53.0 \mathrm{~L} / \mathrm{d}(9.3 \%$ of observed mean).

\section{Input Variables}

Variables that affect $\mathrm{CH}_{4}$ production the most, such as total proportion of concentrate, DMI, OM digestibility, and dietary concentrations of NDF, starch $\mathrm{CP}$, and ether extract were tested against residuals of $\mathrm{CH}_{4}$ emissions (Figure 3). For all variables tested, the proportion of concentrate $(P=0.005)$ and NDF $(P=0.021)$ was significantly related to residuals of $\mathrm{CH}_{4}$ emissions, whereas other variables were not related to residuals. 


\section{DISCUSSION}

The performance of the in vitro system examined in this study was evaluated by investigating the relationship between observed $\mathrm{CH}_{4}$ emissions in vivo and predicted $\mathrm{CH}_{4}$ emissions in a gas in vitro system. Predicted $\mathrm{CH}_{4}$ correlated highly with observed in vivo values $\left(\mathrm{R}^{2}\right.$ $=0.94$ ). The 49 diets used in this study represented differing dietary compositions and covered several feeding parameters that varied in terms of proportion of concentrate, starch, protein, fat, and maturity of forage, to investigate the effect of NDF, digestibility, and level of intake (see Tables 2 and 3 ).

\section{In Vitro $\mathrm{CH}_{4}$ Prediction}

The major advantage of the in vitro system is that a large number of diets can be tested for predicted $\mathrm{CH}_{4}$ emissions and ranked according to $\mathrm{CH}_{4}$ production. The most promising diets or additives can then be selected for in vivo studies. Predicted $\mathrm{CH}_{4}$ data from in vitro tests on different feedstuffs can also be used in calculations such as a life cycle assessment. Moreover, feed additives can be tested as a first step to evaluate potential effects on $\mathrm{CH}_{4}$ production. In the study by Ramin and Huhtanen (2012), where GE concentration of the feed was assumed to be $18.5 \mathrm{MJ} / \mathrm{kg}$ of $\mathrm{DM}$, it was found that the predicted in vitro $\mathrm{CH}_{4}$ production, calculated as energy yield $\left(\mathbf{C H}_{4}-\mathbf{E}\right)$, decreased from 7.8 to $6.0 \%$ of total GE intake with an increased amount of substrate (timothy hay) from 300 to $1,200 \mathrm{mg}$. These values are close to the observed in vivo values at maintenance and production levels of intake in dairy cows (Yan et al., 2000). Based on the predicted $\mathrm{CH}_{4}$ production in the current study, it was possible to calculate the energy loss using the assumption that GE concentration was $18.5 \mathrm{MJ} / \mathrm{kg}$ of DM. This resulted in predicted $\mathrm{CH}_{4}$ within the range 3.9 to $8.8 \% \mathrm{GE}$, which was expected.
When only original diets were analyzed, the prediction error was smaller compared with when reconstituted diets were also included in the analysis. The optimal approach would probably be to use only original diets from in vivo studies for the in vitro test, but it was difficult to get sufficient samples from in vivo respiration chamber studies. Even though more than half of the diets (28/49) had to be reconstituted, a robust relationship was still present between predicted and observed $\mathrm{CH}_{4}$ production $\left(\mathrm{R}^{2}\right.$ for mixed model $\left.=0.96\right)$ when all diets were analyzed.

\section{Study Effect}

The fixed and mixed model regression analyses were used to estimate the relationship between predicted $\mathrm{CH}_{4}$ values from the in vitro system and observed $\mathrm{CH}_{4}$ values. The RMSPE was smaller when the mixed model was used compared with the fixed model $[9.5 \%$ (40.1 L/d) compared with $12.3 \%$ (51.6 L/d) of observed mean, respectively]. Furthermore, the mean bias was not significant when the mixed model was used, but with the fixed model the mean bias effect was significant $(P=$ 0.01). All these findings suggest that the mixed model, where the random study effect was removed from the residual variance, should be used. This random study effect includes differences in calibration of chambers. In a recent study in the United Kingdom, Gardiner et al. (2015) analyzed the accuracy of respiration chambers and concluded that considerable errors in $\mathrm{CH}_{4}$ measurement can occur unless appropriate validation is performed on a regular basis. Similarly, Ramin and Huhtanen (2015) found significant between-laboratory differences in the residuals of both $\mathrm{CH}_{4}$ emissions and $\mathrm{OM}$ digestion in the mechanistic model Karoline predictions. Karoline is a dynamic and mechanistic model describing digestion and metabolism in dairy cows.

\begin{tabular}{|c|c|c|c|c|c|}
\hline Item & $\mathrm{n}$ & Mean & SD & Minimum & Maximum \\
\hline \multicolumn{6}{|c|}{ Diet composition, $\mathrm{g} / \mathrm{kg}$ of $\mathrm{DM}$} \\
\hline $\mathrm{CP}$ & 45 & 182 & 48 & 115 & 405 \\
\hline Ether extract & 41 & 40.1 & 19.3 & 19 & 109 \\
\hline Starch & 41 & 121 & 85 & 3.7 & 324 \\
\hline NDF & 49 & 396 & 80 & 254 & 585 \\
\hline Feed intake, $\mathrm{kg}$ of $\mathrm{DM} / \mathrm{d}$ & 49 & 13.4 & 6.9 & 0.87 & 21.3 \\
\hline $\mathrm{BW}, \mathrm{kg}$ & 45 & 511 & 130 & 89.3 & 637 \\
\hline \multicolumn{6}{|l|}{ Diet digestibility, $\mathrm{g} / \mathrm{kg}$} \\
\hline OM digestibility & 49 & 767 & 53 & 591 & 910 \\
\hline \multicolumn{6}{|l|}{ Methane emissions, L/d } \\
\hline Observed & 49 & 418 & 207 & 35.8 & 664 \\
\hline Predicted & 49 & 399 & 217 & 21 & 734 \\
\hline
\end{tabular}


DMI

Residual analysis indicated a negative slope bias (i.e., observed $\mathrm{CH}_{4}$ increased less than predicted). The slope bias can be due to increased efficiency of microbial protein synthesis with increased DMI (Broderick et al., 2010), which was not taken into account in predicted values. Simulations with the Karoline model have in- dicated that increased efficiency of microbial protein synthesis ( $\mathrm{g}$ of microbial $\mathrm{N}$ per kg of OM truly digested in the rumen) markedly contributes to decreased $\mathrm{CH}_{4}$ yield $(\mathrm{g} / \mathrm{kg}$ of DMI) with increased DMI (Ramin and Huhtanen, 2015). Including the changes in microbial protein synthesis in the prediction model would probably reduce the slope bias between observed and predicted $\mathrm{CH}_{4}$ emissions. Increases in the efficiency of
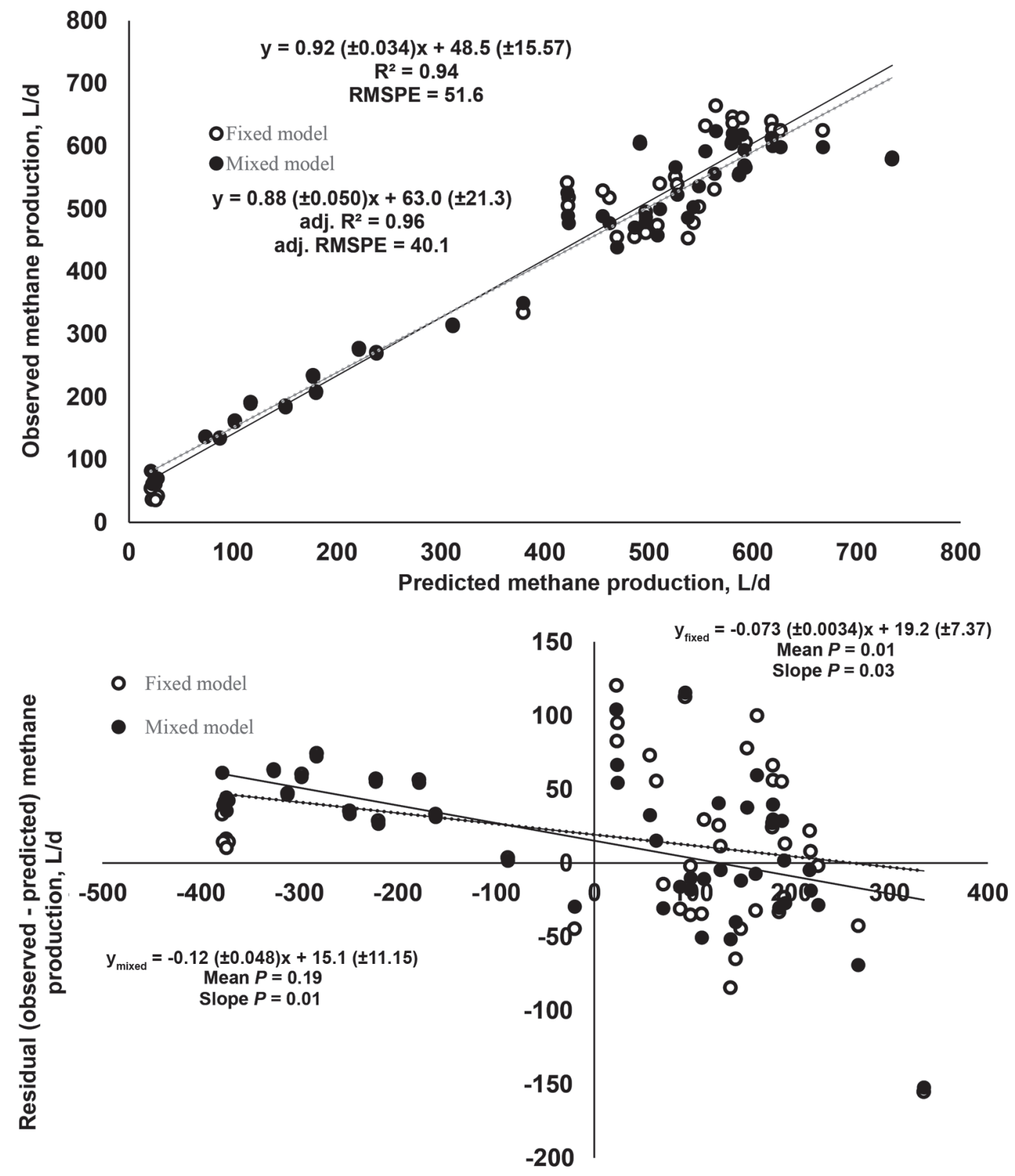

Centered predicted methane production, L/d

Figure 1. (Above) Relationship between predicted methane production in vitro, based on 48-h incubation, and observed methane production in vivo $(\mathrm{L} / \mathrm{d} ; \mathrm{n}=49)$, with fixed and mixed model regression analysis and (below) centered predicted values and residuals (observed - predicted) of methane production $(\mathrm{L} / \mathrm{d} ; \mathrm{n}=49)$. adj. = adjusted; RMSPE $=$ root mean square prediction error. 
microbial protein synthesis partition more fermented carbon to microbial cells, and consequently, less carbon is available for VFA and GP (Blaxter and Clapperton, 1965).

Increased DMI usually increases total $\mathrm{CH}_{4}$ production (Johnson and Johnson, 1995; Ellis et al., 2007; Hristov et al., 2013; Ramin and Huhtanen, 2013), but $\mathrm{CH}_{4}$ yield (g/kg of DMI) decreases with increased DMI (Blaxter and Clapperton, 1965; Yan et al., 2009; Ramin and Huhtanen, 2013). This decrease in $\mathrm{CH}_{4}$ yield at higher feeding levels seems to be related to various factors, one of which may be that an increase in feeding level leads to increased passage rate, which reduces the digestibility of diets and the amount of $\mathrm{H}_{2}$ produced per unit intake, which reduces $\mathrm{CH}_{4}$ yield (Jentsch et al., 2007). In addition, in a recent modeling exercise, Huhtanen et al. (2016) indicated that improved efficiency of microbial synthesis was associated with lower predicted $\mathrm{CH}_{4}$ yield with increased passage rate (shorter RT).

The RT of forage and concentrate in the present study was based on calculations by Cannas et al. (2003), assuming a 1.6-fold longer passage rate for forage than for concentrate. An increase in feeding level is accompanied by an increase in passage rate and therefore rumen RT for microbes is lowered. This increases the efficiency of microbial synthesis and the microbial cell yield (Janssen, 2010) and because microbial cells are more reduced than dietary carbohydrates (Hungate et al., 1971; Czerkawski, 1986), less $\mathrm{H}_{2}$ is available for $\mathrm{CH}_{4}$ production (Russell et al., 1992; Janssen, 2010). An alternative explanation is that when passage rate increases, the $\mathrm{H}_{2}$ concentration in the rumen may increase at first, which in turn gives negative feedback to $\mathrm{H}_{2}$-producing microbes, and thus $\mathrm{H}_{2}$ production and in turn $\mathrm{CH}_{4}$ production are lowered (Janssen, 2010).

An increase in feeding level has also been shown to change the fermentation pattern in the rumen [e.g., causing a decreased acetate to propionate ratio (Sveinbjörnsson et al., 2006)], accompanied by reduced formation of $\mathrm{CH}_{4}$ due to the lower $\mathrm{H}_{2}$ production from fermentation (Moss et al., 2000). Matching the sample size to intake could reduce the slope bias between observed and predicted $\mathrm{CH}_{4}$ production because $\mathrm{CH}_{4}$ yield decreases as the amount of substrates increases.

\section{Residual Analysis}

Residual analysis was used to obtain information on model performance by estimating the relationships between the residuals of $\mathrm{CH}_{4}$ production and the most important input variables known to affect $\mathrm{CH}_{4}$ production. A significant relationship between residuals and input variables indicates errors in the model structure for the corresponding object or linear bias in input data. The significant relationship observed between NDF (g/ $\mathrm{kg}$ ) and the residuals of $\mathrm{CH}_{4}$ emissions may have arisen

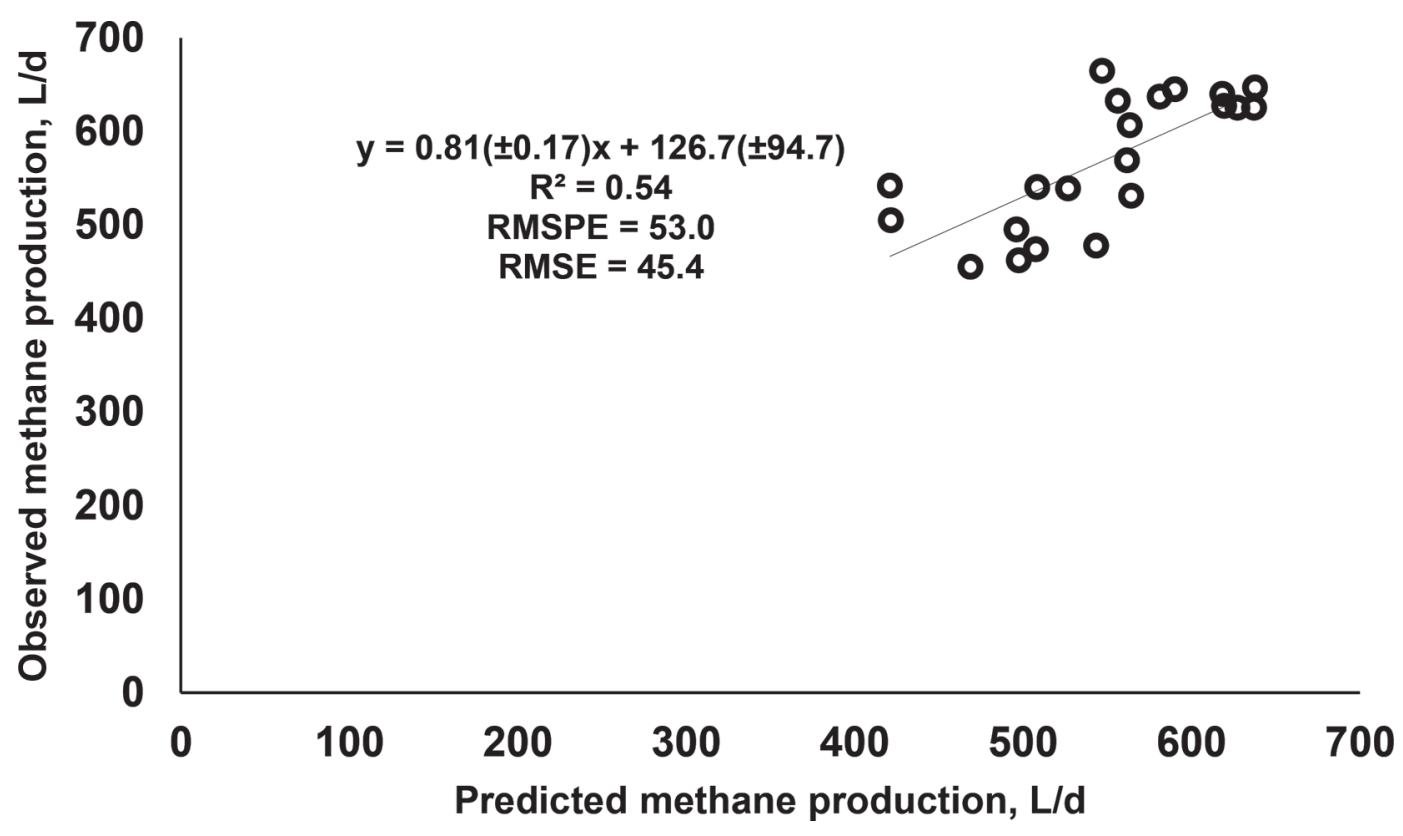

Figure 2. Relationship between predicted methane production in vitro, based on 48-h incubation, and observed methane production (L/d) for original diets from in vivo studies also used for in vitro tests $(\mathrm{n}=21)$, based on fixed model regression analysis. RMSE $=$ root mean square error; RMSPE = root mean square prediction error. 

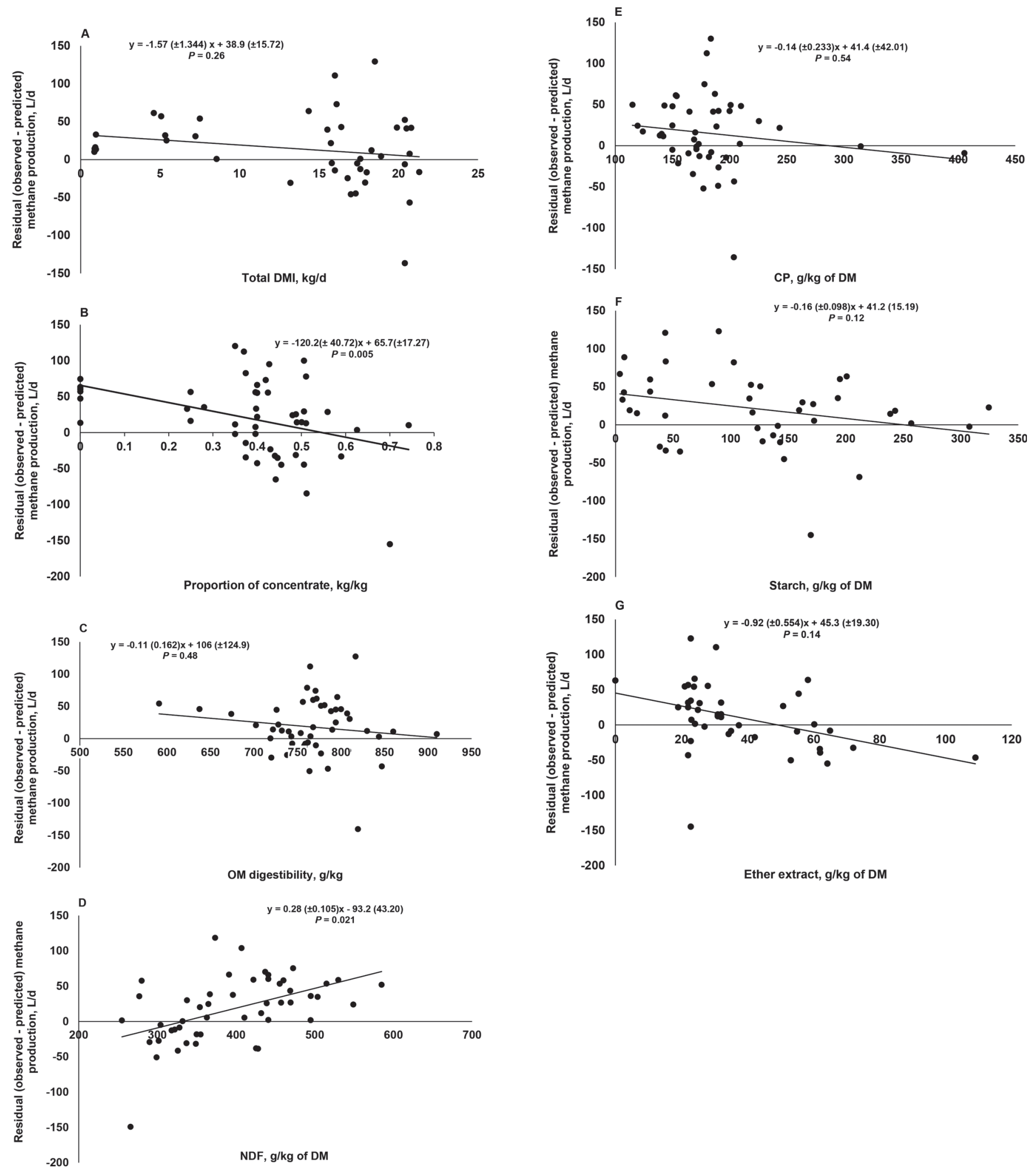

Figure 3. Relationship between input variables (proportion of concentrate, total DMI, OM digestibility, NDF, CP, starch, and ether extract) and residuals of methane production (observed methane production - predicted methane production). 
because the NDF content in the feeds used in vitro was not precisely the same as in the original feed, which could have had an effect on the values.

The proportion of concentrate was significantly related to residual of $\mathrm{CH}_{4}$ production. In addition, the significant relationship occurred because $\mathrm{CH}_{4}$ production responses to proportion of concentrates were different between in vitro and in vivo. Decreases in $\mathrm{CH}_{4}$ production are generally reported in vivo with higher propionate production, especially in growing cattle fed a high-concentrate ( $>90 \%$ on DM basis) feedlot diet (Johnson and Johnson, 1995; Beauchemin and McGinn, 2005), but some studies indicate increases. In the study by Beever et al. (1988), inclusion of barley in the diet increased $\mathrm{CH}_{4}$ production, calculated as $\mathrm{CH}_{4}$ - $\mathrm{E}$ was highest with the highest proportion of barley. A recent study by Jonker et al. (2016) compared $\mathrm{CH}_{4}$ production in vitro and in vivo in sheep fed diets in which alfalfa silage was replaced with increasing levels of starch-rich corn silage or corn grain. They found that an increase in dietary starch concentration up to around $200 \mathrm{~g} / \mathrm{kg}$ in vivo (alfalfa silage:corn silage 50:50) increased $\mathrm{CH}_{4}$ production, but thereafter higher starch concentration decreased $\mathrm{CH}_{4}$ production. This response was not observed in vitro, where an increase in the concentration of starch linearly increased $\mathrm{CH}_{4}$ production in that study. Those authors suggested that the differing results in vivo and in vitro might have been caused by a change in $\mathrm{pH}$ in vivo, whereas in vitro systems are highly buffered (Muetzel et al., 2014) and therefore less sensitive to changes in $\mathrm{pH}$ (Jonker et al., 2016). Furthermore, there seemed to be an interaction between concentrate proportion and feeding level in the study by Moss et al. (1995), where increased proportion of concentrate increased $\mathrm{CH}_{4}$-E/GE numerically more at lower levels of intake. An increase in the concentrate proportion from 0 to $73 \%$ increased $\mathrm{CH}_{4}$-E/GE from 8.3 to $11.3 \%$ at a feeding level around maintenance and from 7.4 to $8.4 \%$ when the level was 1.5 times maintenance (Moss et al., 1995). Differences in $\mathrm{CH}_{4}$ responses with increasing concentrate levels between studies can be related to the effects of type of starch or concentrates on rumen fermentation pattern (Hristov et al., 2013; Guyader et al., 2016). Concentrates typically increase the proportion of propionate, but in the study by Moss et al. (1995) propionate actually decreased numerically and butyrate increased significantly. In addition, Murphy et al. (2000) observed no effect on propionate proportion of increasing concentrate proportion from 50 to $70 \%$. Moreover, Patel et al. (2011) observed no difference in $\mathrm{CH}_{4}$ production between diets with forage:concentrate ratio 50:50, 70:30, and 90:10, with the only observed difference in VFA proportions being in the proportion of butyrate, which was highest in the 50:50 diet. It appears that VFA pattern is considerably influenced by the degree of silage fermentation in grass silage diets (Huhtanen, 1998). Moreover, Friggens et al. (1998) added various supplements to grass-silage-based diets and found that increased starch level seemed to increase butyrate proportion rather than propionate proportion.

The overall increase in $\mathrm{CH}_{4}$ production related to concentrate levels observed in the current study has also been observed in other in vitro studies; for example, Cattani et al. (2014) observed higher $\mathrm{CH}_{4}$ production from concentrates than from forage. Similarly, in the study by Ramin and Huhtanen (2013), barley grain, oat grain, and sugar beet pulp produced more $\mathrm{CH}_{4}$ than the 4 forages tested. The findings in the present study suggest that the in vitro GP method does not predict the effects of concentrate proportion of $\mathrm{CH}_{4}$ production accurately (when the diets are fed at production level, in general, with a much higher level of feeding compared with feeding for maintenance), whereas a good relationship between in vivo and in vitro $\mathrm{CH}_{4}$ production was found at feeding levels around maintenance, as also found by Moss et al. (1995).

\section{Other Effects on Type of Feed In Vivo}

The effect of diet on VFA pattern and $\mathrm{CH}_{4}$ production is complex and it may not always be possible to predict $\mathrm{CH}_{4}$ production accurately by in vitro methods because a particular type of diet may give different effects in different studies. For example, in studies evaluating the proportion of corn silage (increase in dietary starch content) in relation to $\mathrm{CH}_{4}$ production and VFA pattern, the results vary widely, as reviewed by Guyader et al. (2016). In a study by Arndt et al. (2015), replacement of corn silage with alfalfa silage decreased the proportion of propionate without significant effects on $\mathrm{CH}_{4}$ production. However, Brask et al. (2013) found that propionate proportion was much higher in corn silage diets than in grass silage diets, whereas the opposite was shown for acetate proportion, and that this effect on VFA was reflected in lower $\mathrm{CH}_{4}$ production with corn silage diets. In another study examining gradual replacement of grass silage with corn silage, $\mathrm{CH}_{4}$ production varied quadratically and was highest at intermediate levels of corn silage (van Gastelen et al., 2015). No difference was observed in the proportions of acetate and propionate, but the butyrate proportion increased with the level of corn silage inclusion, contradicting expectations. These differing results make it difficult to interpret whether increased levels of starch 
reduce $\mathrm{CH}_{4}$ production in a linear way, or whether there is a threshold for starch inclusion (Sauvant and Giger-Reverdin, 2009).

Fat supplementation of ruminant diets generally has an inhibitory effect on $\mathrm{CH}_{4}$ production, but the degree of inhibition depends on type of diet, source of fat, type of fatty acids, and level of inclusion (Beauchemin et al., 2007; Beauchemin et al., 2008). Because fat is not fermented in the rumen, using fat instead of other fermentable sources reduces the amount of $\mathrm{H}_{2}$ available for use in $\mathrm{CH}_{4}$ production (Johnson and Johnson, 1995). Addition of fat to the diet increases the energy density, which may give less $\mathrm{CH}_{4}$ per kilogram of product of milk or meat. Fat also has an antimicrobial action against protozoa and some cellulolytic bacteria, and the inhibition of cellulolytic microbes shifts in microbial populations, which may increase propionate production (Martin et al., 2010). Biohydrogenation of UFA can be an alternative sink for $\mathrm{H}_{2}$, but incorporation of the $\mathrm{H}_{2}$ produced is small compared with in methanogenesis (Czerkawski and Clapperton, 1984). In the present study, prediction of fat supplementation in vitro produced similar values to observed values.

\section{Effect of In Vitro System}

The overprediction of $\mathrm{CH}_{4}$ production with increasing proportion of concentrate in the in vitro GP system may be due to an effect of inoculum, which may host a degree of variation within in vitro methodology (Mould et al., 2005). To minimize the bias effect of inoculum, the most appropriate method may be to use inoculum from donor animals that have been fed the same diet as tested in vitro, allowing adaptation of microbial flora. Although this may not be possible when testing new additives or many diets at the same time, it is important to be aware of the possible effect of the inoculum. In this study, the donor cows were fed a diet with a forage:concentrate ratio of 60:40, which is quite different from that in several of the diets tested and may have had an effect on the results. Another factor that influences the microbial community structure in the inoculum is the closed system in batch systems, which is different from the continuous system in vivo. The in vivo passage rate and VFA absorption also have a major effect (Dijkstra et al., 1993). In a previous study with a batch culture system, we observed that the relative abundance of Prevotella decreased and unclassified Bacteriodales increased over time in the in vitro system (Danielsson et al., 2014).

The relative abundance of the main genus Prevotella decreased over time and the relative abundance of unclassified Bacteroidales increased. Mateos et al. (2015) compared in vitro fermentation characteristics and bacterial diversity in vivo in sheep with a batch culture system and found a shift in microbial community composition, with a less diverse community in vitro. This shift in community structure may have an effect on the level of substrate degradation and fermentation pattern, which in turn may affect $\mathrm{CH}_{4}$ production. However, the overall fermentation effect of forage was similar for both in vivo and in vitro experiments with sheep studied by Mateos et al. (2015). Composition of the medium used in vitro may affect ruminal fermentation and $\mathrm{CH}_{4}$ production. It has been observed that highly buffered medium may increase acetate to propionate ratio compared with what happens in the rumen, which increases $\mathrm{H}_{2}$ available for $\mathrm{CH}_{4}$ production (Lana et al., 1998). In this study, the medium had an inclusion of $20 \%$ rumen fluid. The composition of $\mathrm{HS}$ gases $\mathrm{CO}_{2}, \mathrm{~N}_{2}$, and $\mathrm{H}_{2}$ may also have an effect on $\mathrm{CH}_{4}$ production (Yáñez-Ruiz et al., 2016). In a study by Patra and Yu (2013), initial $\mathrm{CO}_{2} \mathrm{HS}$ was positively correlated with $\mathrm{CH}_{4}$ production after fermentation. The higher $\mathrm{CH}_{4}$ production may be explained by a direct and greater availability of $\mathrm{CO}_{2}$ in the inoculum that acts as the electron acceptor for the main hydrogenotrophic methanogenesis pathway (Yáñez-Ruiz et al., 2016). This was taken into account in our modeling work (Ramin and Huhtanen 2012). The ratio of $\mathrm{CH}_{4}$ in the outflow has been modeled to $\mathrm{CH}_{4}$ concentration in the HS. It is suggested that further research are essential to understand the effect of a mixture of $\mathrm{CO}_{2}$ and $\mathrm{N}_{2}$ that best mimics rumen gas composition in vivo (Yáñez-Ruiz et al., 2016).

\section{CONCLUSIONS}

The in vitro GP system predicted $\mathrm{CH}_{4}$ production with reasonable accuracy and precision. The residuals were not significantly related to most factors known to affect $\mathrm{CH}_{4}$ production. However, the effect on $\mathrm{CH}_{4}$ production of increased NDF concentration was underpredicted and the effect of increased proportion of concentrate was overpredicted. The in vitro GP system seems not to be applicable for evaluation of concentrate proportion, especially at high intake levels. The main area of application is screening of ingredients and assessing the effect of feed additives on methane production, digestibility, and digestion kinetics. However, any in vitro mitigation effect studies must be confirmed in vivo before practical application.

\section{ACKNOWLEDGMENTS}

Financial support from the Swedish Research Council Formas is gratefully acknowledged. Thanks also to Ann- 
Sofi Hahlin for her laboratory assistance. This study has been made possible by the Swedish Infrastructure for Ecosystem Science (SITES) at Röbäcksdalen.

\section{REFERENCES}

Allen, M. S., and D. R. Mertens. 1988. Evaluation constraints of fiber digestion by rumen microbes. J. Nutr. 118:261-270.

Arndt, C., J. M. Powell, M. J. Aguerre, and M. A. Wattiaux. 2015. Performance, digestion, nitrogen balance, and emission of manure ammonia, enteric methane, and carbon dioxide in lactating cows fed diets with varying alfalfa silage-to-corn silage ratios. J. Dairy Sci. 98:418-430.

Beauchemin, K. A., M. Kreuzer, F. O'Mara, and T. A. McAllister. 2008. Nutritional management for enteric methane abatement: A review. Anim. Prod. Sci. 48:21-27.

Beauchemin, K. A., S. McGinn, C. Benchaar, and L. Holtshausen 2009. Crushed sunflower, flax, or canola seeds in lactating dairy cow diets: Effects on methane production, rumen fermentation, and milk production. J. Dairy Sci. 92:2118-2127.

Beauchemin, K. A., S. McGinn, T. F. Martinez, and T. A. McAllister 2007. Use of condensed tannin extract from quebracho trees to reduce methane emissions from cattle. J. Anim. Sci. 85:1990-1996.

Beauchemin, K. A., and S. M. McGinn. 2005. Methane emissions from feedlot cattle fed barley or corn diets. J. Anim. Sci. 83:653-661.

Beever, D. E., S. B. Cammell, C. Thomas, M. C. Spooner, M. J. Haines, and D. L. Gale. 1988. The effect of date of cut and barley substitution on gain and on the efficiency of utilization of grass silage by growing cattle. Br. J. Nutr. 60:307-319.

Bertilsson, J., and M. Murphy. 2003. Effects of feeding clover silages on feed intake, milk production and digestion in dairy cows. Grass Forage Sci. 58:309-322.

Blaxter, K. L., and J. L. Clapperton. 1965. Prediction of the amount of methane produced by ruminants. Br. J. Nutr. 19:511-522.

Brask, M., P. Lund, A. L. F. Hellwing, M. Poulsen, and M. R. Weisbjerg. 2013. Enteric methane production, digestibility and rumen fermentation in dairy cows fed different forages with and without rapeseed fat supplementation. Anim. Feed Sci. Technol. 184:67-79.

Broderick, G. A., P. Huhtanen, S. Ahvenjärvi, S. M. Reynal, and K. J. Shingfield. 2010. Quantifying ruminal nitrogen metabolism using the omasal sampling technique in cattle-A meta-analysis. J. Dairy Sci. 93:3216-3230.

Cannas, A., P. J. Van Soest, and A. N. Pell. 2003. Use of animal and dietary information to predict rumen turnover. Anim. Feed Sci. Technol. 106:95-117.

Cattani, M., F. Tagliapietra, L. Maccarana, H. H. Hansen, L. Bailoni, and S. Schiavon. 2014. Technical note: In vitro total gas and methane production measurements from closed or vented rumen batch culture systems. J. Dairy Sci. 97:1736-1741.

Cone, J. W., A. H. van Gelder, G. J. W. Visscher, and L. Oudshoorn 1996. Influence of rumen fluid and substrate concentration on fermentation. Anim. Feed Sci. Technol. 61:113-128.

Czerkawski, J. W. 1986. An Introduction to Rumen Studies. Robert Maxwell, M. C., Oxford, UK.

Czerkawski, J. W., and G. Breckenridge. 1977. Design and development of a long-term rumen simulation technique (Rusitec). Br. J. Nutr. 38:371-384.

Czerkawski, J. W., and J. L. Clapperton. 1984. Fats in Animal Nutrition. Pages 249-264 in Proc. 37th Nottingham Easter School. J. Wiseman, ed. Butterworths, London, UK.

Danfær, A., P. Huhtanen, P. Udén, J. Sveinbjörnsson, and H. Volden. 2006. The Nordic dairy cow model, Karoline - description. Pages 383-406 in Nutrient Digestion and Utilisation in Farm Animals: Modelling Approaches. E. Kebreab, J. Dijkstra, W. J. Bannink, J. Gerrits, and J. France, ed. CAB International, CABI Publishing, Wallingford, UK.

Danielsson, R., A. Werner-Omazic, M. Ramin, A. Schnürer, M. Griinari, J. Dicksved, and J. Bertilsson. 2014. Effects on enteric methane production and bacterial and archaeal communities by the addition of cashew nut shell extract or glycerol-An in vitro evaluation. J. Dairy Sci. 97:5729-5741.

Dijkstra, J., H. Boer, J. Van Bruchem, M. Bruining, and S. Tamminga. 1993. Absorption of volatile fatty acids from the rumen of lactating dairy cows as influenced by volatile fatty acid concentration, $\mathrm{pH}$ and rumen liquid volume. Br. J. Nutr. 69:385-396.

Ellis, J. L., E. Kebreab, N. E. Odongo, B. W. McBride, E. K. Okine, and J. France. 2007. Prediction of methane production from dairy and beef cattle. J. Dairy Sci. 90:3456-3466.

Friggens, N. C., G. C. Emmans, I. Kyriazakis, J. D. Oldham, and M. Lewis. 1998. Feed intake relative to stage of lactation for dairy cows consuming total mixed diets with a high or low ratio of concentrate to forage. J. Dairy Sci. 81:2228-2239.

Gardiner, T. D., M. D. Coleman, F. Innocenti, J. Tompkins, A. Connor, P. C. Garnsworthy, J. M. Moorby, C. K. Reynolds, A. Waterhouse, and D. Wills. 2015. Determination of the absolute accuracy of UK chamber facilities used in measuring methane emissions from livestock. Measurement 66:272-279.

Gidlund, H., M. Hetta, S. J. Krizsan, S. Lemosquet, and P. Huhtanen. 2015. Effects of soybean meal or canola meal on milk production and methane emissions in lactating dairy cows fed grass silagebased diets. J. Dairy Sci. 98:8093-8106.

Guyader, J., H. H. Janzen, R. Kroebel, and K. A. Beauchemin. 2016. Forage use to improve environmental sustainability of ruminant production. J. Anim. Sci. 94:3147-3158.

Hammond, K. J., S. Muetzel, G. G. Waghorn, C. S. Pinares-Patino, J. L. Burke, and S. O. Hoskin. 2009. The variation in methane emissions from sheep and cattle is not explained by the chemical composition of ryegrass. Proc. N.Z. Soc. Anim. Prod. 69:174-178.

Hook, S. E., A. D. G. Wright, and B. W. McBride. 2010. Methanogens: Methane producers of the rumen and mitigation strategies. Archaea 2010:945785.

Hristov, A. N., J. Oh, J. L. Firkins, J. Dijkstra, E. Kebreab, G. Waghorn, H. P. S. Makkar, A. T. Adesogan, W. Yang, C. Lee, and P. J. Gerber. 2013. Special topic-Mitigation of methane and nitrous oxide emissions from animal operations: I. A review of enteric methane mitigation options. J. Anim. Sci. 91:5045-5069.

Huhtanen, P. 1998. Supply of nutrients and productive responses in dairy cows given diets based on restrictively fermented silage. Agric. Food Sci. 7:219-250.

Huhtanen, P., M. Ramin, and E. H. Cabezas-Garcia. 2016. Effects of ruminal digesta retention time on methane emissions: A modelling approach. Anim. Prod. Sci. 56:501-506.

Huhtanen, P., A. Seppälä, M. Ots, S. Ahvenjärvi, and M. Rinne. 2008. In vitro gas production profiles to estimate extent and effective first-order rate of neutral detergent fiber digestion in the rumen. J. Anim. Sci. 86:651-659.

Hungate, R. E., J. Reichl, and R. Prins. 1971. Parameters of rumen fermentation in a continuously fed sheep: Evidence of microbial rumination pool. Appl. Microbiol. 22:1104-1113.

Janssen, P. H. 2010. Influence of hydrogen on rumen methane formation and fermentation balances through microbial growth kinetics and fermentation thermodynamics. Anim. Feed Sci. Technol. 160:1-22.

Jentsch, W., M. Schweigel, F. Weissbach, H. Scholze, W. Pitroff, and M. Derno. 2007. Methane production in cattle calculated by the nutrient composition of the diet. Arch. Anim. Nutr. 61:10-19.

Johnson, K., M. Huyler, H. Westberg, B. Lamb, and P. Zimmerman. 1994. Measurement of methane emissions from ruminant livestock using a sulfur hexafluoride tracer technique. Environ. Sci. Technol. $28: 359-362$.

Johnson, K. A., and D. E. Johnson. 1995. Methane emissions from cattle. J. Anim. Sci. 73:2483-2492.

Jonker, A., K. Lowe, S. Kittelmann, P. H. Janssen, S. Ledgard, and D. Pacheco. 2016. Methane emissions changed nonlinearly with graded substitution of alfalfa silage with corn silage and corn grain in the diet of sheep and relation with rumen fermentation characteristics in vivo and in vitro. J. Anim. Sci. 94:3464-3475.

Keady, T. W. J., and C. S. Mayne. 1998. The effect of concentrate energy source on silage feeding behaviour and energy utilization 
by lactating dairy cows offered grass silages with differing intake characteristics. Anim. Sci. 67:225-236.

Knapp, J. R., G. L. Laur, P. A. Vadas, W. P. Weiss, and J. M. Tricarico. 2014. Invited review: Enteric methane in dairy cattle production: Quantifying the opportunities and impact of reducing emissions. J. Dairy Sci. 97:3231-3261.

Krizsan, S. J., S. Ahvenjärvi, and P. Huhtanen. 2010. A meta-analysis of passage rate estimated by rumen evacuation with cattle and evaluation of passage rate prediction models. J. Dairy Sci. 93:5890-5901.

Lana, R. P., J. B. Russell, and M. E. Van Amburgh. 1998. The role of $\mathrm{pH}$ in regulating ruminal methane and ammonia production. J. Anim. Sci. 76:2190-2196.

Littell, R. C., G. A. Milliken, W. W. Stroup, and R. D. Wolfinger. 1996. SAS System for Mixed Models. SAS Inst. Inc., Cary, NC.

Madsen, J., B. S. Bjerg, T. Hvelplund, M. R. Weisbjerg, and P. Lund. 2010. Methane and carbon dioxide ratio in excreted air for quantification of the methane production from ruminants. Livest. Sci. 129:223-227.

Martin, C., D. P. Morgavi, and M. Doreau. 2010. Methane mitigation in ruminants: From microbe to the farm scale. Animal 4:351-365.

Mateos, I., M. J. Ranilla, C. Saro, and M. D. Carro. 2015. Comparison of fermentation characteristics and bacterial diversity in the rumen of sheep and in batch cultures of rumen microorganisms. J. Agric. Sci. 153:1097-1106.

Menke, K. H., and H. Steingass. 1988. Estimation of the energetic feed value obtained from chemical analysis and in vitro gas production using rumen fluid. Anim. Res. Dev. 28:7-55.

Moss, A. R., D. I. Givens, and P. C. Garnsworthy. 1995. The effect of supplementing grass silage with barley on digestibility, in sacco degradability, rumen fermentation and methane production in sheep at two levels of intake. Anim. Feed Sci. Technol. 55:9-33.

Moss, A. R., J. P. Jouany, and J. Newbold. 2000. Methane production by ruminants: Its contribution to global warming. Ann. Zootech. 49:231-253.

Mould, F. L., K. E. Kliem, R. Morgan, and R. M. Mauricio. 2005. In vitro microbial inoculum: A review of its function and properties. Anim. Feed Sci. Technol. 123:31-50.

Muetzel, S., C. Hunt, and M. H. Tavendale. 2014. A fully automated incubation system for the measurement of gas production and gas composition. Anim. Feed Sci. Technol. 196:1-11. https://doi.org/ 10.1016/j.anidietsci.2014.05.016.

Murphy, M., M. Åkerlind, and K. Holtenius. 2000. Rumen fermentation in lactating cows selected for milk fat content fed two forage to concentrate ratios with hay or silage. J. Dairy Sci. 83:756-764.

Patel, M., E. Wredle, G. Börjesson, R. Danielsson, A. D. Iwaasa, E. Spörndly, and J. Bertilsson. 2011. Enteric methane emissions from dairy cows fed different proportions of highly digestible grass silage. Acta Agric. Scandinavica A Anim. Sci. 61:128-136.

Patra, A. K., and Z. Yu. 2013. Effects of gas composition in headspace and bicarbonate concentrations in media on gas and methane production, degradability, and rumen fermentation using in vitro gas production techniques. J. Dairy Sci. 96:4592-4600.

Ramin, M., and P. Huhtanen. 2012. Development of an in vitro method for determination of methane production kinetics using a fully automated in vitro gas system-A modelling approach. Anim. Feed Sci. Technol. 174:190-200.

Ramin, M., and P. Huhtanen. 2013. Development of equations for predicting methane emissions from ruminants. J. Dairy Sci. 96:24762493.

Ramin, M., and P. Huhtanen. 2015. Nordic dairy cow model Karoline in predicting methane emissions: 2. Model evaluation. Livest. Sci. 178:81-93.

Russell, J. B., J. D. O'connor, D. G. Fox, P. J. Van Soest, and C. J. Sniffen. 1992. A net carbohydrate and protein system for evaluating cattle diets: I. Ruminal fermentation. J. Anim. Sci. 70:35513561.

Sauvant, D., and S. Giger-Reverdin. 2009. Modélisation des interactions digestives et de la production de méthane chez les ruminants. INRA Prod. Anim. 22:375-384. (In French.)
Schofield, P., R. E. Pitt, and A. N. Pell. 1994. Kinetics of fiber digestion from in vitro gas production. J. Anim. Sci. 72:2980-2991.

St-Pierre, N. R. 2003. Reassessment of biases in predicted nitrogen flows to the duodenum by NRC 2001. J. Dairy Sci. 86:344-350.

Sveinbjörnsson, J., P. Huhtanen, and P. Udén. 2006. The Nordic dairy cow model, Karoline-development of volatile fatty acid sub-model. Pages 1-14 in Nutrient Digestion and Utilization in Farm Animals: Modelling Approaches. CAB International, Wallingford, UK.

Tyrrell, H. F., D. J. Thomson, D. R. Waldo, H. K. Goering, and G. L. Haaland. 1992. Utilization of energy and nitrogen by yearling Holstein cattle fed direct-cut alfalfa or orchardgrass ensiled with formic-acid plus formaldehyde. J. Anim. Sci. 70:3163-3177.

van Gastelen, S., E. C. Antunes-Fernandes, K. A. Hettinga, G. Klop, S. J. J. Alferink, W. H. Hendriks, and J. Dijkstra. 2015. Enteric methane production, rumen volatile fatty acid concentrations, and milk fatty acid composition in lactating Holstein-Friesian cows fed grass silage-or corn silage-based diets. J. Dairy Sci. 98:1915-1927.

van Nevel, C. J., and D. I. Demeyer. 1981. Effect of methane inhibitors on the metabolism of rumen microbes in vitro. Arch. Tierernahr. $31: 141-151$.

Yan, T., R. E. Agnew, F. J. Gordon, and M. G. Porter. 2000. Prediction of methane energy output in dairy and beef cattle offered grass silage-based diets. Livest. Prod. Sci. 64:253-263.

Yan, T., C. S. Mayne, F. G. Gordon, M. G. Porter, R. E. Agnew, D. C. Patterson, C. P. Ferris, and D. J. Kilpatrick. 2010. Mitigation of enteric methane emissions through improving efficiency of energy utilization and productivity in lactating dairy cows. J. Dairy Sci. 93:2630-2638.

Yan, T., M. G. Porter, and C. S. Mayne. 2009. Prediction of methane emission from beef cattle using data measured in indirect opencircuit respiration calorimeters. Animal 3:1455-1462.

Yáñez-Ruiz, D. R., A. Bannink, J. Dijkstra, E. Kebreab, D. P. Morgavi, P. O'Kiely, C. K. Reynolds, A. Schwarm, K. J. Shingfield, Z. $\mathrm{Yu}$, and A. N. Hristov. 2016. Design, implementation and interpretation of in vitro batch culture experiments to assess enteric methane mitigation in ruminants-A review. Anim. Feed Sci. Technol. 216:1-18.

\section{APPENDIX}

List of publications describing the diets used in the in vitro study.

Beever, D. E., S. B. Cammell, C. Thomas, M. C. Spooner, M. J. Haines, and D. L. Gale. 1988. The effect of date of cut and barley substitution on gain and on the efficiency of utilization of grass silage by growing cattle. Br. J. Nutr. 60:307-319.

Brask, M., P. Lund, A. L. F. Hellwing, M. Poulsen, and M. R. Weisbjerg. 2013a. Enteric methane production, digestibility and rumen fermentation in dairy cows fed different forages with and without rapeseed fat supplementation. Anim. Feed Sci. Technol. 184:67-79.

Brask, M., P. Lund, M. R. Weisbjerg, A. L. F. Hellwing, M. Poulsen, M. K. Larsen, and T. Hvelplund. 2013b. Methane production and digestion of different physical forms of rapeseed as fat supplements in dairy cows. J. Dairy Sci. 96:2356-2365.

Ferris, C. P., F. J. Gordon, D. C. Patterson, M. G. Porter, and T. Yan. 1999. The effect of genetic merit and concentrate proportion in the diet on nutrient utilization by lactating dairy cows. J. Agric. Sci. $132: 483-490$

Gidlund, H., M. Hetta, S. J. Krizsan, S. Lemosquet, and P. Huhtanen. 2015. Effects of soybean meal or canola meal on milk production and methane emissions in lactating dairy cows fed grass silagebased diets. J. Dairy Sci. 98:8093-8106.

Gordon, F. J., M. G. Porter, C. S. Mayne, E. F. Unsworth, and D. J. Kilpatrick. 1995. Effect of forage digestibility and type of concentrate on nutrient utilization by lactating dairy cattle. J. Dairy Res. $62: 15-27$. 
Hellwing, A. L. F., M. Brask, P. Lund, and M. R. Weisbjerg. 2013 Effect of carbohydrate source and rumen $\mathrm{pH}$ on enteric methane from dairy cows. Pages 206-208 in Emissions of Gas and Dust From Livestock. INRA, Saint-Malo, France.

Jentsch, W., H. Wittenburg, and R. Schiemann. 1972. Die Verwertung der Futterenergie für die Milchproduktion. 4. Mitteilung. Untersuchungen der Futterenergie bei Rapsoleinsatz. Arch. Tierernahr. 22:697-720.

Keady, T. W. J., and C. S. Mayne. 1998. The effect of concentrate energy source on silage feeding behaviour and energy utilization by lactating dairy cows offered grass silages with differing intake characteristics. Anim. Sci. 67:225-236.

Kirkpatrick, D. E., R. W. J. Steen, and E. F. Unsworth. 1997. The effect of differing forage: Concentrate ratio and restricting feed intake on the energy and nitrogen utilization by beef cattle. Livest. Prod. Sci. 51:151-164.

Moss, A. R., and D. I. Givens. 2002. The effect of supplementing grass silage with soya bean meal on digestibility, in sacco degradability rumen fermentation and methane production in sheep. Anim. Feed Sci. Technol. 97:127-143.

Moss, A. R., D. I. Givens, and P. C. Garnsworthy. 1995. The effect of supplementing grass silage with barley on digestibility, in sacco degradability, rumen fermentation and methane production in sheep at two levels of intake. Anim. Feed Sci. Technol. 55:9-33.

Tyrrell, H. F., D. J. Thomson, D. R. Waldo, H. K. Goering, and G. L. Haaland. 1992. Utilization of energy and nitrogen by yearling Holstein cattle fed direct-cut alfalfa or orchardgrass ensiled with formic-acid plus formaldehyde. J. Anim. Sci. 70:3163-3177. 